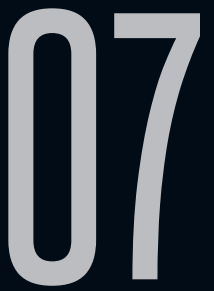

\title{
MARGINAIS DE UM PASSADO FUTURISTA: O NASCIMENTO DO GÊNERO STEAMPUNK NOS EUA E SUA PRIMEIRA RECEPÇÃO NO BRASIL ${ }^{1}$
}

Enéias Tavares (UFSM)

Recebido em 04 nov 2019. Enéias Tavares é Doutor com tese que trata da arte Aprovado em 23 mar 2020. poética e pictórica de William Blake (2012). Possui graduação em Letras Português/Inglês e respectivas Literaturas pela Universidade Federal de Santa Maria (2005). Mestre em Literatura Comparada (2008) pela mesma instituição sob orientação do Prof. Dr. Lawrence Flores Pereira. Durante a escrita da dissertação, traduziu Otelo: O Mouro de Veneza", de Shakespeare, trabalho que recebeu montagem teatral sob a direção de Aline Castaman no mesmo ano. Em 2011, realizou parte de sua formação (doutorado sanduíche) na Universidade de York (Inglaterra) sob orientação do professor Michael Phillips e no Morley College of London, onde reproduziu a técnica usada pelo artista inglês para criar seus livros iluminados. É pesquisador do Laboratório Corpus e professor adjunto do Departamento de Letras Clássicas e Linguística, onde atuou como chefe de departamento entre 2013 e 2014 no Centro de Artes e Letras da UFSM. Em 2014, publicou $A$ lição de anatomia do temível dr. Louison, primeiro volume da série de ficção retrofuturista Brasiliana Steampunk, romance ganhador do Prêmio Fantasy, da Casa da Palavra/LeYa. Em 2017, junto de AZ Cordenonsi e Nikelen Witter, publicou o romance

1 Título em inglês: "Marginals of a futurist past: The birth of the steampunk gender in the USA and its first reception in Brazil" 
A Alcova da Morte, primeiro volume da série de ficção científica e fantasia Guanabara Real. No ano seguinte, o romance foi o ganhador dos prêmios LeBlanc (Melhor Romance Fantástico de 2017) e AGES (Melhor Romance Juvenil de 2017). É organizador de dois volumes (Editora UFSM, 2014 e 2017) de "Discursos do Corpo na Arte"'", em parceria com Gisela Biancalana e Mariane Magno. Em 2018, pela editora Arte \& Letra, publicou "Fantástico Brasileiro: O insólito Literário do Romantismo ao Fantasismo", livro escrito em parceria com Bruno Anselmi Matangrano e decorrente de exposição itinerante que mapeia a história da literatura fantástica em nosso país. No mesmo ano, lançou com o ilustrador Fred Rubim a HQ A Todo Vapor!, quadrinho inspirado na série audiovisual homônima, tanto em formato Webcomic quanto em formato impresso. Na Pós-Graduação é orientador de trabalhos que envolvem Literatura Fantástica Brasileira, os Livros Iluminados de William Blake e a relação entre Poesia e Pintura no Século XIX, além de ministrar na UFSM o Curso Livre Escrita de Ficção, curso que decorre de seu projeto de extensão e coluna mensal no Portal CosmoNerd intitulados Bestiário Criativo. Trabalha há oito anos na Universidade Aberta do Brasil (UAB) como Professor-pesquisador do Curso de Letras a Distância, tendo produzido material para as disciplinas de EaD Literatura Greco-Latina, Introdução aos Estudos Literários I e II, Literatura, Outra Artes e Mídias e Produção Textual: Escrita de Ficção, disciplina que também ministra como Curso Livre no Espaço Multidisciplinar UFSM - Silveira Martins. Em 2019, criou o ORC Studio, laboratório multifuncional de Economia Criativa que fomenta a produção de livros, jogos, quadrinhos e projetos audiovisuais.

Resumo: No decorrer da década de 1980, muitos escritores de ficção científica e fantasia reinterpretaram o espírito "punk" da década anterior, enfatizando cenários insólitos, realidades 
alternativas e fantasias alocadas no passado ou no futuro. Um elemento central a essas histórias era a presença de heróis marginais, párias sociais e minorias étnicas que pouco espaço ganharam em exemplares do gênero nas décadas anteriores, uma vez que seus respectivos autores ainda preferiam heróis caucasianos idealizados, vítimas femininas em perigo e ameaças malignas, de preferência de origem intergaláctica ou oriental. Na contracorrente dessa produção, três autores estadunidenses passaram a produzir histórias nas quais a revisão fantástica do passado preconizou problemas sociais e reflexões políticas pertinentes ao seus tempos. Neste ensaio, analisarei três romances fundadores do steampunk, bem como seu impacto nos anos seguintes, em especial no cenário literário brasileiro.

Palavras-Chave: Steampunk; Ficção Científica; Historiografia

Abstract: Throughout the 1980s, many science fiction and fantasy writers reinterpreted the "punk" spirit of the previous decade, emphasizing the unusual scenarios, alternate realities, and fantasies allocated in past or future. Central to these stories is the presence of marginal heroes, social outcasts, and ethnic minorities that gain little ground in previous fictions, as their authors still prefer idealized Caucasian heroes, female victims and dangerous and malignant villains, preferably of eastern origins. In the countercurrent of this production, three NorthAmerican authors produced stories in which the fantastic review of the past advocates social problems and political reflections related to their times. In this essay, we analyze three novels considered as founders of genre, as well as their impact in the coming years, both upon steampunk production and upon Brazilian literary scene.

Keywords: Steampunk; Science fiction; Literary Historiography. 


\section{INTRODUÇÃO}

Neste artigo, discutirei em primeiro lugar como três autores estadunidenses de ficção científica na década de 1980 reinterpretaram o espírito punk da década anterior, enfatizando cenários insólitos, realidades alternativas e fantasias alocadas em um passado hipotético. Falo aqui de Morlock nigh (1979) de K. W. Jeter, de Anubis Gates (1983) de Tim Powers, e de Homunculus (1986) de James Blaylock, três obras que são fundadoras do steampunk, modo narrativo derivado da ficção científica e também estética apropriada por cineastas, game designers, estilistas, músicos e outros artistas.

Parte da inovação proposta nessas obras esteve em valorizar heróis marginais, párias sociais e minorias étnicas que pouco espaço ganhavam em exemplares do gênero. Ao contrário, nas décadas anteriores, muitos autores da tradição anglófona ainda preferiam heróis caucasianos idealizados, vítimas femininas em perigo e ameaças malignas, de preferência de origem intergaláctica ou oriental. Na contracorrente dessa produção, Jeter, Powers e Blaylock produziram enredos nas quais a revisão fantástica do passado preconizou problemas sociais e reflexões políticas contemporâneas.

A partir disso, veremos quais seriam os principais elementos constitutivos do steampunk e como ele foi, anos depois, acolhido no contexto literário brasileiro e por suas comunidades de fãs e leitores. Para tanto, discutiremos a criação do grupo Conselho Steampunk, fundado em 2008, e as duas primeiras coletâneas publicadas em nosso país: Steampunk - Histórias de um passado extraordinário, de 2009, e Vaporpunk: Relatos steampunk publicados sob as ordens das suas majestades, de 2010. 


\section{PUNKS, HEROÍNAS E MONSTROS: A CRIAÇÃO DO STEAMPUNK}

Para entendermos a origem do steampunk, é preciso que entendamos a formação do próprio conceito. Num primeiro momento, seu surgimento está ligado a outro modo narrativo de ficção científica comum na década de 1980: o cyberpunk. Definido de forma abrangente como uma representação ficcional de um high tech, low life, o Cyberpunk aproxima um grande desenvolvimento tecnológico de uma crise social, cultural e econômica, na qual seres humanos sobrevivem em meio a um selvagem mundo pósindustrial, ultra capitalista e multicultural.

Lawrence Person, em seu "Notes Toward a Postcyberpunk Manifesto", descreveu do seguinte modo os habitantes desse novo mundo futurista:

Classic cyberpunk characters were marginalized, alienated loners who lived on the edge of society in generally dystopic futures where daily life was impacted by rapid technological change, an ubiquitous datasphere of computerized information, and invasive modification of the human body. [...] Cyberpunk characters frequently seek to topple or exploit corrupt social orders. [...] In cyberpunk, technology facilitates alienation from society. $(1998, \mathrm{~s} / \mathrm{p})^{2}$

Nenhum autor ou obra resumem melhor os temas centrais do cyberpunk do que o romance de William Gibson, Neuromancer

2 "Clássicos personagens cyberpunk são marginalizados, solitários alienados que vivem nos limites da sociedade em futuros geralmente distópicos nos quais a vida diária foi impactada por rápidas mudanças tecnológicas, uma infosfera ubíqua de informação computadorizada, além de invasivas modificações dos corpos humanos. [...] Personagens cyberpunk frequentemente buscam derrubar ou explorar ordens sociais corruptas. [...] No cyberpunk, a tecnologia facilita a alienação da sociedade." Nota: Esta e futuras traduções, salvo identificação, são de autoria do autor do artigo. 
(1984). Nele, temos um mundo niilista, sombrio e sinistro, no qual poderes totalitários estatais foram substituídos por grandes corporações que têm no livre comércio e no capitalismo agressivo seus pilares. Nestas "distopias pós-industriais", o futuro esperançoso e ordenado - e também distante das ficções futuristas dos séculos XIX e XX - deu lugar a uma proximidade temporal desesperadora, caótica e multifacetada, muitas vezes borrando as fronteiras entre o hoje e o amanhã.

O que aconteceria, porém, se autores, em vez de imaginarem um futuro distópico a partir desses temas e ansiedades, se concentrassem num passado que poderia ter acontecido? Pensando neste conjunto de insatisfações econômicas, sociais e existências o lema do punk setentista -, como reinventar um passado que foi marcado por uma profunda idealização dos extratos sociais nobres, caucasianos e patriarcais? Nesse sentido, o que Jeter, Powers e Blaylock fizeram foi unir o marginal ao vapor - o punk ao steam promovendo com isso uma revisão crítica do passado ao invés de uma comum reprodução idealizada.

Os três autores eram jovens californianos, amigos e admiradores do escritor e guru da contracultura Philip K. Dick, e viviam de produzir histórias de ficção científica. Nos finais de dia, entre recusas de originais e procura por trabalho, o trio se reunia no O'Hara's Old Towne Pub, em Orange, Califórnia, para beber, revisar manuscritos e trocar ideias. O pub ainda existe e fica a poucos quilômetros da Chapman University, onde hoje Blaylock e Powers são professores. Fascinava aos três autores a obra jornalística seminal London labour and the London poor (1851), de Henry Mayhew. Sobre esses encontros e a importância da obra de Mayhew, Blaylock lembra: 
We'd attended the same University, read the same Victorian novels, essays and poetry, and shared the same fascination with the language and the trappings of the Victorian era. We lived within a couple of miles of each other, which gave us the opportunity to hang around together doing 'research' at O'Hara's Pup in downtown Orange, among other places. It was during one of these long afternoons that K. W. [Jeter] told Tim and I about Henry Mayhew's London books, which I mined when I wrote my novel Hommunculus. (Apud ROBB, 2012, p.6) ${ }^{3}$

London Labour foi essencial aos três autores por revelar uma cidade na qual as castas de nobrezas, as reuniões de alta cúpula e os charmes das roupas e das carruagens pouco apareciam. Antes, o que Mayhew fez, ainda no século XIX, foi produzir um importante registro histórico que além de desconstruir a névoa de civilidade que recobria a visão comum do período vitoriano, revelava uma cidade anárquica e suja permeada de desejos obscuros, segredos inconfessáveis e habitantes desfavorecidos e marginalizados. Foi a partir desta perspectiva, pensando em como jogar uma ideia de futuro distópico num passado igualmente sombrio e opressivo, que os três primeiros romances steampunk nasceram.

O primeiro deles foi Morlock night, de K. W. Jeter, publicado em 1979. O enredo se situa em 1892, quando certo cavalheiro chamado Edwin Hocker ouviu sobre a misteriosa Máquina do Tempo de um enigmático doutor de nome Ambrose. Este revelou a Hocker que 3 "Frequentávamos a mesma universidade, liamos os mesmos romances, ensaios e poemas vitorianas e compartilhávamos o mesmo fascínio pela linguagem e pelos ornamentos da era vitoriana. Morávamos a alguns quilômetros um do outro, o que nos deu a oportunidade de sairmos, pesquisando no O'Hara's Pup, no centro de Orange, entre outros lugares. Foi durante uma dessas tardes que K. W. [Jeter] contou a Tim e a mim sobre os livros de Mayhew sobre Londres, dos quais tirei muita coisa para o romance Hommunculus." 
o inventor original deixou o portal aberto - continuando assim o enredo de A Máquina do tempo, de H. G. Wells - e que agora a Londres vitoriana está na iminência do ataque dos demoníacos Morlocks. Em Wells, morlocks são monstros canibais que evoluíram das classes operárias oprimidas. No futuro, eles se alimentarão dos frágeis Eloi, seres fracos e incapazes de se defender. No romance de Jeter, num direto diálogo com Wells, trata-se de imaginar um mundo sendo consumido por uma ameaça criada pelos próprios humanos. Tal diálogo daria origem a uma das principais características do steampunk, ou seja, a releitura e recriação de obras do passado.

De forma rocambolesca, Ambrose se revela o mago Merlin e ele e Hocker partem numa missão em busca de um ressuscitado Rei Arthur. Este estranho plot twist dá conta da origem deste projeto. Originalmente, Jeter e Tim Powers, além de Ray Nelson, foram contatados para escrever uma série de romances que reinterpretasse o mito arturiano em diferentes épocas. No caso de Jeter, este escolheu a Londres vitoriana. Depois de iniciarem o trabalho, o projeto foi abandonado pela editora que o havia encomendado. Powers usaria sua pesquisa em duas de suas obras, The Drawinng of the dark (1979) e Last call (1992), enquanto Jeter uniu essa temática à outra de suas paixões: o romance de H. G. Wells. ${ }^{4}$

4 Sobre isso, Powers, na introdução de uma nova edição de Morlocknight, relata: "I believe it was early in 1976 that Roger Elwood told K. W. Jeter, Ray Nelson and I that a British Publisher wanted a series of ten books based on the idea of King Arthur being reincarnated throughout the centuries, obligingly reappearing whenever England needed rescuing. The three of us agreed to write them, and we got together to divvy up history, being sure to leave enough years between adventures for Arthur to have time to been born and grow to adulthood. As I recall, we kind of haggled over various dates, but Jeter came away with the clear claim on Victorian England. I'm glad now that Nelson and I missed grabbing that slot - neither of us could have written anything like Morlock night. The deal with the British publisher fell apart, but Morlock night found an American publisher, and then a different British one, and readers on both side of the Atlantic got to experience Jeter's unique Victorian London" (2011, p.8). 
Quanto ao protagonista de Morlock night, Edwin Hocker, trata-se de um homem de seu tempo, com todos os elementos questionáveis à sensibilidade contemporânea: Hocker é sexista, classicista e excessivamente racional. Em oposição a ele, porém, Jeter cria Tafe, uma mulher vinda de um futuro apocalíptico. Tafe é uma personagem fascinante por sua impetuosidade e determinação, além de constituir em seu próprio figurino uma personalidade incomum, vestindo roupas masculinas e fumando. É justamente em contato com essa protagonista feminina que Hocker vem a adotar no decorrer da narrativa uma visão mais igualitária no que concerne aos gêneros. Além disso, percebemos em Morlock night uma inversão de papéis clássicos, visto que não é a personagem principal que protege a vítima feminina em perigo - como acontece, por exemplo, com o protagonista de A Máquina do tempo, que salva a Eloi Weeva de se afogar. Em Morlock night, é Tafe que salva Hocker de ser atacado e morto pelos morlocks.

Quanto ao conflito de classes, que estaria presente numa visão mais atenta sobre os Morlocks na narrativa de Wells, Jeter o atualiza, agora detalhando fisicamente os monstruosos inimigos, algo que o narrador da obra original não faz. Embora não existam traços, nem mesmo potenciais, de percepção simpática diante da alteridade dos morlocks, o detalhamento físico de sua raça acaba por materializar a gradativa coisificação de seres humanos sob o punho de ferro da opressão política ou industrial.

Como terceiro elemento diferenciador entre as duas obras, Jeter cria uma Londres bem diferente da de Wells. Enquanto neste vemos a Londres vitoriana presente e a futura devastada, em Jeter temos a aglutinação dos dois tempos - passado e futuro - 
no próprio enredo: trata-se da Londres do passado atacada por morlocks do futuro. A visão de Jeter expressa assim a condição contemporânea, que vê na constituição do presente marcas de um futuro que já chegou, mesmo tendo sido construído sobre os valores do passado. O steampunk encontra-se nessa justaposição de dissonantes temporalidades.

Com Anubis gates, de Tim Powers, publicado em 1983, a história começa no nosso presente, com o milionário J. Cochran Darrow descobrindo um portal temporal que o levará a 1810, para assistir a uma conferência de Samuel Taylor Coleridge. Para tanto, ele contata o classicista Brendan Doyle, um homem melancólico que pranteia a morte da esposa em um acidente automobilístico. Este aceita o convite de acompanhar Darrow, não apenas pelo interesse por Coleridge como pela esperança de encontrar o poeta William Ashbless, por quem é fascinado, tendo já escrito um livro sobre ele. ${ }^{5}$

O que dá início ao conflito da trama é o rapto de Doyle por um grupo de magos egípcios, liderado pelo maligno Dr. Romany. Este deseja controlar a tecnologia temporal para arruinar o império inglês, uma vez que os ingleses conquistaram e pilharam sua terra natal. Fará isso com um plano de vingança que envolve a morte do próprio rei e o incêndio de Londres. No meio disso, o leitor acompanha o desajeitado e inexpressivo protagonista tentando 5 Uma das grandes surpresas de Anubis Gates é a presença do poeta fictício William Ashbless. Criado por Powers e Blaylock na década anterior como um mero exercício ficcional, os dois submeteram alguns poemas do pretenso poeta a uma revista literária, e para a sua surpresa, os poemas foram aceitos. Quando receberam uma carta convidando Ashbless para dar uma palestra sobre sua poesia, foram em seu lugar, explicando que o poeta tinha uma deformação física e que não aparecia em público. Depois da apresentação, ambos riram da piada e das reações entusiasmadas dos professores diante da pretensa "excelência poética" de Ashbless. No site oficial de Powers há a biografia do poeta e alguns de seus poemas, sendo que ele voltaria a aparecer em algumas outras obras dos dois autores. 
tanto salvar sua vida como impedir os planos de Romany. Mal podendo sobreviver na Londres oitocentista, ele se une a uma trupe de mendigos liderada por Horribin, um criminoso que usa maquiagem de palhaço para esconder sua deformidade. No enredo secundário, temos uma jovem mulher que se veste de garoto de rua e que usa o nome Jacky. Seu objetivo com o disfarce é perseguir o assassino em série Dog-Face Joe, que matou seu noivo.

Em Anubis gates, outras três características que se tornariam caras ao steampunk são utilizadas. Primeiro, a ênfase em heróis marginais que, não raro, são justamente as figuras heroicas que empurram a trama do romance para frente. Segundo, na figura de Jecky temos mais uma personagem feminina instigante e inovadora, dessa vez aludindo às comuns criações de identidades masculinas por parte de mulheres com os mais variados objetivos, estando os literários e os sociais entre eles. Por fim, destacamos a criação de Ashbless e a forma como o steampunk motiva tanto a recriação da história convencionalmente aceita quanto a inserção de elementos ficcionais a linha do tempo tradicional. Essa revisão de classes sociais e a representação de figuras então deixadas à sombra, além do elaborado diálogo entre temporariedades reais e imaginárias, marcariam obras futuras do mesmo modo narrativo.

Por fim, com Homunculus, publicado em 1986, James Blaylock introduz o seu herói regular, o doutor/explorador/professor Langdon St. Ives. A trama tem início em 1879, quando um dirigível desgovernado sobrevoa Londres, chamando a atenção da Sociedade Real, da qual Langdon é integrante. Ao seu lado está Shiloh, um neo-evangelista dúbio, que está convencido de que a nave carrega o corpo de seu pai alienígena. A nave, na verdade, 
também esconde a criatura que dá título ao romance. Interessados em seus tripulantes estão o cientista Ignatio Narbondo e o milionário inescrupuloso Kelso Drake. Ambos suspeitam que a nave e seu capitão escondem o segredo da imortalidade. Em Blaylock, trata-se de uma Londres mágica e surreal, com mais elementos fantásticos do que os outros dois romances.

Também aqui, há elementos que se tornariam comuns ao steampunk: a criação de heróis regulares, a utilização de tropos comuns à ficção científica e a utilização da ironia para dar novo fôlego a temas um tanto banais do gênero, como o ataque alienígena ou o cientista louco. No centro do enredo vertiginoso está o leitor, que pode explorar uma Londres que não existiu. Blaylock, que continuaria seu universo em outros romances, demonstrou que o passado poderia constituir um baú de surpresas ficcionais e reais, a espera de ser revisitado, revisado e recriado por autores e leitores.

Seria mais fácil vermos o trabalho de Jeter, Powers e Blaylock como exclusiva revisão da tradição oitocentista permeada por uma visão histórica mais afinada à crítica social. Essa leitura, não incorreta, mas incompleta, muitas vezes os reduz a releituras das obras de Mary Shelley, H. G. Wells e Julio Verne. Porém, o que os três autores fizeram também corresponde às frustrações pós-punk da década de 1980 e à cena literária na qual estavam inseridas, permeada pela FC e pelas publicações pulp. Sobre isso, Brian J. Robb, escreve:

The current mainstream incarnation of Steampunk was anticipated by the work of various science fiction authors in the 1970, who, instead of looking towards the future, turned their sensibilities to the 
past. Fuelled by a cultural and social nostalgia for the modern world, these authors took their cues from the 'scientific romances' of Wells and Verne. Writers such as Moorcock, Steaphen Baxter and Christopher Priest reworked (and in doing so, critiqued) the ideas expresses in those ur-texts. Priest made Wells a character in The Space Machine (1976), while Baxter riffed on Wells's creations with The Time Ships (1995). However, Moorcocks's Oswald Bastable books, which began in 1971 with The Warlord of the Air, were not content to simply function as a nostalgic recreation of such Victorian fantasises, but also served as a critique of the Victorian and Edwardian periods' technological optimism, which was to result in the carnage of the Great War of 1914-18. (2012, p.9) ${ }^{6}$

A união dessa "nostalgia cultural e social do mundo moderno" a uma visão crítica das "fantasias vitorianas" seria central ao steampunk enquanto modo narrativo. E talvez, essa seja uma das razões de ele ter tamanho apelo junto a audiências contemporâneas. Diferente de narrativas idealizadas e um tanto simplistas alocadas num passado que denega classes, gêneros e outras ansiedades sociais e culturais, o steampunk é uma revisão crítica, ácida e por vezes irônica das nossas visões do passado e do quanto elas ainda moldam, infelizmente, nosso presente.

6 "A atual encarnação mainstream do Steampunk foi antecipada pelo trabalho de vários autores de ficção científica na década de 1970, que, em vez de olhar para o futuro, voltaram suas sensibilidades ao passado. Alimentados por uma nostalgia cultural e social do mundo moderno, esses autores foram inspirados pelos 'romances científicos' de Wells e Verne. Porém, escritores como Moorcock, Steaphen Baxter e Christopher Priest reformularam (e, ao fazê-lo, criticaram) as ideias expressas nesses textos. Priest fez de Wells um personagem em The Space Machine (1976), enquanto Baxter tocou nas criações de Wells com The Time Ships (1995). No entanto, as aventuras de Oswald Bastable, de Moorcock, que começaram em 1971 com The Warlord of the Air, não se contentavam em apenas funcionar como uma recriação nostálgica de tais fantasias vitorianas, como também serviam como uma crítica ao otimismo tecnológico dos períodos vitoriano e eduardino, que levaram ao massacre da I Grande Guerra." 
No ano seguinte à publicação de Homunculus, Jeter publicou Infernal devices, livro que consolidaria o novo modo narrativo e chamaria a atenção de um público cada vez mais interessado nessas histórias sobre heróis marginais, passados improváveis e tramas recicladas de forma inovadora. Havia apenas um problema: como chamar esse tipo de literatura que inegavelmente já existia, porém sob nenhuma nomenclatura? A resposta a essa pergunta veio na seção de cartas da revista de ficção científica Locus, em abril de 1987. Respondendo à resenha de Faren Miller sobre Infernal devices, Jeter escreveu:

Dear Locus:

Enclosed is a copy of my 1979 novel Morlock night; I'd appreciate your being so good as to route it to Faren Miller, as it's a prime piece of evidence in the great debate as to who in "the Powers/Blaylock/ Jeter fantasy triumvirate" was writing in the "gonzohistorical manner" first. Though of course, I did find herreview in the March Locus to be quite flattering. Personally, I think Victorian fantasies are going to be the next big thing, as long as we can come up with a fitting collective for Powers, Blaylock and myself. Something based on the appropriate technology of that era; like "steampunks", perhaps...

--K.W. Jeter" (LOCUS, 1987)

Depois de resumir a obra de Jeter, em especial Morlock night, como uma "combinação de H. G. Wells, fantasia arturiana e cultura 7 "Querida Locus, / Segue em anexo uma cópia do meu romance de 1979, Morlock night. Eu apreciaria que você fizesse a gentileza de encaminhá-lo a Faren Miller, uma vez que se trata de uma das principais evidências no grande debate sobre quem no 'triunvirato de fantasia de Powers / Blaylock / Jeter' estava escrevendo do 'modo duplo-histórico' primeiro. É óbvio, claro, que eu achei a resenha dele na Locus de março bastante lisonjeira. / Pessoalmente, eu penso que fantasias vitorianas serão o próprio sucesso do momento, desde que tenhamos um termo adequado para o que eu, Powers e Blaylock fazemos. Algo que seja apropriado à tecnologia daquela época, algo como 'steampunks', talvez... / K. W. Jeter". 
oitocentista numa mistura estranha e divertida", Miller colocou nos seguintes termos a sugestão de Jeter: "Steampunks? Gostei...". E pelo visto, muitos também gostaram, uma vez que o termo não só foi abraçado como veio a denominar obras diversas e em múltiplas mídias.

\section{ADMIRÁVEL MUNDO VELHO: UM STEAMPUNK BRASILEIRO}

Nos anos seguintes à carta a revista Locus, o trio fundador publicaria outras obras steampunk, como Infernal devices: A mad victorian fantasy (1987), de Jeter, On stranger sides (1987) e The stress of her regard (1989), de Powers, e Lord Kelvin's machine (1992), de Blaylock. Porém, caberiam a outros autores e autoras a ampliação do gênero. Na década de 1990, por exemplo, o steampunk se consolidou como um modo narrativo instigante tanto na literatura quanto em outras artes e mídias.

No cenário literário norte-americano, canadense e francês, em especial, foram publicados A máquina diferencial (1990), de William Gibson e Bruce Sterling, Confissões de um autômato comedor de ópio (1999), de Fabrice Collin e Mathieu Gaborit, O equilíbrio dos paradoxos (1999), de Michel Pagel, Só a lua o sabe (2000), de Johan Heliot, Mortal engines (2001), de Philip Reeve, The Steampunk Trilogy (1995), de Paul Di Filippo, A corte do ar (2007), de Stephen Hunt, e, apenas em 2009, Boneshaker, de Cherie Priest, Alma - O protetorado da sombrinha, de Gail Carriger, e Leviathan, de Scott Westerfeld. Em 2011, para destacarmos mais dois títulos, seriam publicados nos EUA Sociedade dos meninos gênios, de Lev. A.C. Rosen, e $O$ circo mecânico Tresaulti, de Genevieve Valentine.

Alguns desses títulos foram publicados no Brasil por diferentes editoras, como é o caso de Gibson e Sterling, Reeve, Hunt, Priest, 
Garriger, Westerfeld, Rosen e Valentine, evidenciando que em termos literários, o steampunk tinha muito a oferecer. Além disso, a crescente utilização de sua estética no cinema, nos quadrinhos, nos games e na moda - com especial destaque para duas coleções do estilista Alexander McQueen -, garantiram-Ihe grande visibilidade.

No caso do Brasil, o steampunk chegou no final dos anos 2000, através de dois fenômenos importantes: comunidades de fãs e editores que viram nele uma possível tendência. No primeiro caso, foi em meados de 2008, em São Paulo, quando o ilustrador Karl Felippe passou uma madrugada explicando ao analista de sistemas Raul Cândido o que era o steampunk, e como aquele modo narrativo que ambos adoravam tinha nome, origem e defensores apaixonados. Noites depois, Cândido veio com a ideia de criarem um blog. Quando este foi ao ar, Cândido entrou em contato com Bruno Accioly, que havia criado o site www.steampunk.com.br com o mesmo intuito.

Juntos, acabaram criando um grupo que daria ferramentas para quem quisesse fazer o mesmo onde quer que morasse. Nascia assim o "Conselho Steampunk", cujo nome e estrutura em "lojas" revelam uma referência irônica a divisões de grupos e ordens que eram tão comuns no século XIX. É claro que mesmo com essas referências, os preceitos do grupo, como o conceito de cada núcleo ter sua própria independência, olhavam mais para frente do que para trás, vindo das ideias de Pronoia e Adocracia, além da filosofia Zippie. Nessa acepção, cada um poderia participar do seu modo, de acordo com suas predileções e disponibilidades. A iniciativa brasileira espelha também outras ações semelhantes em países como EUA, Escócia, França e Portugal. 
Sem objetivos comerciais ou hierárquicos, o Conselho é, depois de dez anos, a maior referência em termos de uma iniciativa organizada e voluntária, que encontra nos seus idealizadores constante inspiração: Cândido ministra cursos e palestras sobre o assunto, Accioly é tanto autor quanto ilustrador de obras steampunk, enquanto Karl também se aventura na escrita, além de assinar uma série de ilustrações para projetos e séries literárias de temática steampunk.

A partir dessa efervescência cultural e da chegada de mais obras traduzidas, surgiram as duas primeiras coletâneas steampunk em nosso país. São elas que doravante analisaremos como pioneiras na exploração da paisagem, dos temas e características tanto do cenário brasileiro quanto da língua portuguesa, exercício que se estenderiam em obras posteriores.

Com organização de Gianpaolo Celli, Steampunk: Histórias de um Passado Extraordinário (Tarja) foi a primeira obra steampunk a ser publicada em nosso país. O volume receberia alguns anos depois uma honrosa menção da Steampunk Bible, publicação de Jeff VanderMeer e S. J. Chambers que comentou os movimentos culturais e publicações steampunk até o ano de 2011. Em Steampunk, os autores Alexandre Lancaster, Antonio Luiz M. C. Costa, Claudio Villa, Flávio Medeiros, Fábio Fernandes, Jacques Barcia, Roberto de Sousa Causo e Romeu Martins, além de Celli, explorariam variadas facetas dessa estética retrofuturista, produzindo histórias de ambientação nacional e estrangeira, numa variação de histórias de aventura, suspense e drama. Passemos agora à análise dos contos que compõem o volume. 
"O assalto ao trem pagador", de Gianpaolo Celli, apresenta uma tríade de aventureiros inventores, cada um associado a uma sociedade secreta diversa: a prussiana Bella Formumm, uma Illuminatus; um francês chamado Samuel Pilcher, um franco-maçon; e o brasileiro Cláudio Bonadei, da ordem Rosacruz. O objetivo do trio é roubar um potente carregamento que ameaça a unificação da Alemanha no final do século XIX. Neste conto, ambientado na Inglaterra e com várias referências ao Brasil, não apenas por seu protagonista, mas também pela escola de Aeronáutica que ele representa, o detalhamento de dados históricos, personagens reais e informações sobre a tecnologia do período preparam o desenvolvimento do enredo para o seu clímax, no qual vemos o assalto prometido no título.

Em "Uma breve história da maquinidade”, de Fábio Fernandes - um autor e tradutor experiente e já com grande bagagem nas searas da ficção científica tanto brasileira quanto estadunidense temos por protagonista Victor Frankenstein, tendo este avançado de seus experimentos criativos com criaturas orgânicas para testes com autômatos robóticos. Tendo início em Genebra em 1801, numa alusão à turbulenta noite criativa que originou a história de Mary Shelley, o conto abrange um século e aglutina a história da Europa no século XIX e início do XX com a evolução dos autômatos, culminando em um conflito entre criador e criatura. A linguagem é fluida, além dos dados históricos e tecnológicos estarem equilibrados numa trama envolvente estilo "linha do tempo".

No bem-humorado "A flor de estrume", Antonio Luiz M. C. Costa relê tanto heróis de Machado de Assis - Brás Cubas, Quincas Borba, Lobo Neves e Simão Bacamarte - quanto os avanços médicos 
e científicos do século XX, porém ambientando-os um século antes. Além disso, há portentos inventivos como carruagens mecânicas e feras autômatas - com especial destaque para um dragão a vapor. De resto, o conto revisa de forma interessante a capital paulistana - com aspectos que identificam fauna, flora e cultura - da perspectiva do narrador carioca. Por fim, a releitura da ironia de Machado demonstra que o steampunk nacional não apenas relê - como fizeram respectivamente Celli e Fernandes - história e literatura europeia, como também geografia e ficção brasileiras.

No conto de Alexandre Lancaster, "A música das esferas", estamos agora no Rio de Janeiro, numa trama de assassinato. Envolvidos indiretamente, uma dupla de amigos, Eduardo e Adriano Monserrat - o primeiro, um jornalista, o segundo, um engenheiro - decide investigar o morto, o engenheiro e inventor Waldecyr Bontempo. Entre seus papeis, projetos e inventos, pode estar a solução para sua morte. A trama é leve, muitas vezes centrandose nas relações entre os dois amigos e em suas inexperiências amorosas, com destaque para a prostituta Glorinha e a moça de família Mariana, filha de Simão Barravento, um dos suspeitos do crime que dá mote ao conto. Aqui, a trama parece prevalecer sobre a ambientação histórica e tecnológica, apesar destas estarem presentes como pano de fundo.

De ambientação inicial paulistana, "O plano de Robida: Um Voyage extraordinaire", de Roberto de Sousa Causo, primeiramente apresenta seu antagonista, levemente inspirado numa figura histórica: Robida é um pirata cientista, uma figura vilanesca e ambiciosa que deseja tomar o poder do império brasileiro com poderosas armas de guerra, armas que envolvem dirigíveis aéreos, 
terrestres e submarinos. A figuras ficcionais como o herói militar Ulisses Brasileiro, Causo opõe uma série de figuras históricas como Santos Dumont, Barão de Mauá, Julio Verne, Augusto Zaluar e Padre Landell de Moura. Dividido em cinco partes, a novela abre com a tentativa de Robida de roubar um poderoso invento de Dumont, numa batalha aérea detalhista e vibrante, que dá lugar ao sequestro dos heróis e ao embate com o vilão.

O conflito envolve a busca pelo reino perdido de Atlântida e a colonização alemã no norte do Brasil. A cidade mítica estaria no meio da Amazônia, na cidade de Eterna - numa homenagem à tradição difundida por Jerônimo Monteiro, a quem o texto é dedicado. Robida é um dos textos mais instigantes da antologia, trabalhando igualmente espaço, ambientação e caracterização, aprofundando nesse caso dois de seus personagens. Primeiramente, Robida, que de vilão um tanto cartunesco passa a déspota com tons de complexidade ao defender a libertação de minorias oprimidas pelo império e a expansão dos domínios humanos em direção às estrelas. Tais delírios e excessos, porém, são desnudados por Larsinie uma princesa atlante raptada pelo vilão e com quem Ulisses se relacionará e que ganha espaço na narrativa.

Se os contos anteriores nos levaram a explorações aéreas e terrestres, "O dobrão de prata", de Claudio Villa, leva-nos a uma aventura submarina, desta vez, de nítida inspiração lovecraftiana. O conto de horror demora a revelar sua relação com a temática retrofuturista, até o protagonista - Charles Dexward - ser levado de Brighton ao porto de Liverpool para contratar os serviços de um explorador marítimo chamado Steam Joe. Desse encontro, tem início uma típica exploração - tanto em enredo quanto em 
tropos e linguagem - da ficção lovecraftiana. Apesar de fornecer interessantes participações especiais como a de Robert Howard, o conto explora pouco o tema tecnológico e histórico, preferindo aprofundar o processo obsessivo de seu protagonista em busca do perdido galeão San Juan e seu tesouro perdido, num final igualmente terrífico e um tanto quanto previsível.

Um traço comum em muitas obras de ficção científica é o tema tecnológico e científico se sobressair aos conflitos humanos e aos dramas psicológicos. O conto de Jacques Barcia, "Uma vida possível atrás das barricadas", tinha tudo para incorrer nessa característica, uma vez que seu enredo apresenta, em meio a um conflito bélico, a paixão entre um autômato, Fritz, e uma gólem, Chaya. Porém, sua prosa explora os sentimentos, pensamentos e angústias do robótico e do monstro com delicadeza. A premissa é instigante, unindo a racionalidade robótica ao mistério arcano da magia, exemplificada e reposicionada no casal de protagonistas, um robô sentimental demais e um monstro místico absolutamente pragmático. Enquanto fogem do seu passado, a bordo de um dirigível que ruma às terras livres de Catalônia, sonham com um rebento que possa nascer de sua improvável união.

Quando o conflito bélico chega, o leitor acompanha sua luta por sobrevivência em meio à guerra e à violência. Barcia opõe esses temas a rápidas reflexões sobre amor, arte e existência, criando um dos contos mais criativos do volume. Exceto por duas rápidas referências ao Brasil, o conto se passa num cenário abstrato e idealizado, apesar de mesmo este ser tocado pela destruição humana, destruição que não poupa nem máquinas nem monstros. 
"Cidade Phantástica", de Romeu Martins, abre com uma ambientação western - referenciando o steampunk norte-americano em contraste com o europeu - na qual um trem que faz a ligação Manaus - Rio de Janeiro é tomado por uma gangue de lusitanos chineses vindos de Macau e intitulada Malta do Vapor. A ação é vertiginosa e serve para nos apresentar os protagonistas. De um lado, o policial João Octavio Ribeiro, vulgo João Fumaça. De outro, a jovem Maria Pinto, noiva de um ambicioso industrial norte-americano chamado Mr. Gibson. Este é o possível responsável pelo assalto que abre o conto, além de ser o idealizador da Cidade Phantástica, um prédio moderno no centro do Rio de Janeiro imperial.

Gibson compete com seu sócio no empreendimento, o Barão de Mauá. Além de Copacabana, os dois desejam também alterar o topo do Corcovado com uma estátua de Dom Pedro II. O conto termina com uma interessante história de ação, aludindo ao velho tema da viagem à lua. Encerram a narrativa notas nas quais Martins esclarece suas inspirações para os personagens - numa homenagem, por exemplo, a Octavio Aragão e Gerson Lodi-Ribeiro - bem como referência históricas e ficcionais, com especial atenção a Conan Doyle, Machado de Assis e Bernardo Guimarães, entre outros.

Concluindo a antologia, "Por um fio", de Flávio Medeiros, apresenta uma épica batalha marítima, ambientada no estreito do Canal da Mancha, entre forças inglesas, francesas e norteamericanas. Aqui, o embate entre um submarino e um dirigível militar, tendo o capitão do primeiro - o narrador do conto - de decidir entre sacrificar sua tribulação ou enfrentar seu inimigo. 0 detalhamento da linha temporal alternativa criada por Medeiros ajuda o leitor a entender o conflito do protagonista, além de auxiliar 
na tensão da trama. Quanto à identidade do narrador e de seu algoz, Medeiros deixa a surpresa para as últimas páginas, surpresa que tanto engatilha o conflito do conto como também presta uma homenagem a uma das principais inspirações do steampunk e da ficção científica: Julio Verne.

Enquanto características do volume, identificamos alguns padrões que revelam temas e elementos que constituem esse primeiro exercício ficcional do steampunk em nosso país. Fiquemos com três deles: cenário utilizado, ambientação histórico-geográfica e/ou tecnológica e caracterização, com ênfase no conflito ou no aprofundamento de personagens. Esses dados - expostos na Tabela I - nos permitirão avaliar quantitativamente quais temas estão mais e menos presentes nesses contos.

\begin{tabular}{|c|c|c|c|c|c|}
\hline \multirow[b]{2}{*}{ CONTO E AUTOR } & \multirow[b]{2}{*}{ CENÁRIO } & \multicolumn{2}{|c|}{ AMBIENTAÇÃO } & \multicolumn{2}{|c|}{ CARACTERIZAÇÃO } \\
\hline & & \begin{tabular}{c|} 
Detalhamento \\
Histórico/Geográfico
\end{tabular} & $\begin{array}{l}\text { Detalhamento } \\
\text { Tecnológico }\end{array}$ & $\begin{array}{l}\text { Aprofundamento } \\
\text { Psicológico }\end{array}$ & $\begin{array}{l}\text { Aprofundamento } \\
\text { do Conflito }\end{array}$ \\
\hline $\begin{array}{l}\text { "Assalto ao Trem Pagador", } \\
\text { de Gianpaolo Celli }\end{array}$ & $\begin{array}{l}\text { Europa, } \\
\text { Inglaterra }\end{array}$ & $\mathrm{x}$ & $\mathrm{x}$ & & $\mathrm{x}$ \\
\hline $\begin{array}{l}\text { "Uma Breve História da Maquinidade", } \\
\text { de Fabio Fernandes }\end{array}$ & $\begin{array}{l}\text { Europa, Alemanha e } \\
\text { Inglaterra }\end{array}$ & $\mathrm{x}$ & $\mathrm{x}$ & & $\mathrm{x}$ \\
\hline $\begin{array}{c}\text { "A Flor de Estrume", } \\
\text { de Antonio Luiz M. C. Costa }\end{array}$ & $\begin{array}{c}\text { Brasil, } \\
\text { São Paulo }\end{array}$ & $\mathrm{x}$ & $\mathrm{x}$ & & $\mathrm{x}$ \\
\hline $\begin{array}{l}\text { "A Música das Esferas", } \\
\text { de Alexandre Lancaster }\end{array}$ & $\begin{array}{c}\text { Brasil, } \\
\text { Rio de Janeiro }\end{array}$ & $\mathrm{x}$ & & $\mathrm{x}$ & $\mathrm{x}$ \\
\hline $\begin{array}{l}\text { "O Plano de Robida", } \\
\text { de Roberto de Sousa Causo }\end{array}$ & $\begin{array}{l}\text { Brasil, São Paulo e } \\
\text { Selva Amazônica }\end{array}$ & $\mathrm{x}$ & $\mathrm{x}$ & $\mathrm{x}$ & $\mathrm{x}$ \\
\hline $\begin{array}{l}\text { "O Dobrão de Prata" } \\
\text { Claudio Villa }\end{array}$ & $\begin{array}{l}\text { Europa, } \\
\text { Inglaterra }\end{array}$ & & & $\mathrm{x}$ & $\mathrm{x}$ \\
\hline $\begin{array}{l}\text { Uma Vida Possivel Através das Barricadas" } \\
\text { Jacques Barcia }\end{array}$ & Catalônia & $\mathrm{x}$ & $\mathrm{x}$ & $\mathrm{x}$ & $\mathrm{x}$ \\
\hline $\begin{array}{l}\text { "Cidade Phantástica", } \\
\text { de Romeu Martins }\end{array}$ & $\begin{array}{c}\text { Brasil, } \\
\text { Rio de Janeiro }\end{array}$ & $\mathrm{x}$ & $\mathrm{x}$ & & $\mathrm{x}$ \\
\hline $\begin{array}{l}\text { "Por um Fio", } \\
\text { de Flavio Medeiros }\end{array}$ & $\begin{array}{c}\text { Europa, } \\
\text { Canal da Mancha }\end{array}$ & $\mathrm{x}$ & $\mathrm{x}$ & & $\mathrm{x}$ \\
\hline
\end{tabular}

No que tange à ambientação, há quatro autores que recriam cenários estrangeiros - Celli, Fernandes, Villa e Medeiros - e quatro que utilizam paisagens brasileiras - Costa, Lancaster, Causo e Martins -, com Barcia utilizando um mundo secundário. Sobre essa característica, Éverly Pegoraro lê as histórias desse volume como tendo 
um pano de fundo bélico ou disputas por domínio de tecnologia, de armamentos, de descobertas científicas. As narrativas exploram as tentativas de controle de comportamento social, por meio da utilização das conquistas científico-tecnológicas pelos grupos detentores do poder. Dos nove contos que compõem a coletânea, sete envolvem direta ou indiretamente guerra e tecnologia. Os outros dois abordam, respectivamente, uma descoberta científica no campo da medicina e uma invenção com alto poder destruidor. $(2017$, p.552)

Esse enfoque na ambientação, seja ela histórica ou tecnológica, acaba por, segundo a autora, diminuir o espaço da "vida privada das personagens. Uma ou outra característica desse ambiente pode incrementar os contos, mas é a cidade que se fixa como elemento definidor de subjetividade e interação dos personagens" (2017, p.554). ${ }^{8}$

Portanto, no que concerne aos dois grupos de elementos que identificam ambientação e caracterização, todos os autores, com exceção de Villa e Lancaster, criam histórias nas quais o detalhamento da linha do tempo, da geografia alterada e dos inventos tecnológicos ganham mais destaque do que as personagens ou a própria trama. Logo o mesmo, como era de se esperar, não acontece com a ênfase dada ao aprofundamento psicológico dos personagens. Enquanto todos os contos apresentam conflitos externos definidos, o desenvolvimento psicológico dos personagens ganha maior destaque apenas nos textos de Villa, Lancaster, Causo e Barcia.

8 Além de Pegoraro, destacamos também os trabalhos de Jayme Soares Chaves, cuja dissertação Viagens Extraordinárias e ucronias ficcionais: uma possível arqueologia do steampunk na literatura, apresenta uma rápida análise dos contos da coletânea, bem como o trabalho de Telma Maria Vieira ("A diversidade dos gêneros discursivos: da ficção científica ao steampunk"), que analisa um dos contos da coletânea: "A flor de estrume". Para uma lista completa de livros publicados no Brasil, ver capítulo sobre steampunk no livro Fantástico Brasileiro (Arte \& Letra, 2018). 
Um ano depois, o brasileiro Gerson Lodi-Ribeiro e o português Luís Filipe Silva organizaram VaporPunk: Relatos Steampunk Publicados sob as Ordens de Suas Majestades (Draco) coletânea que, já em seu Prefácio, propõe contos de ambientação brasileira ou portuguesa, respondendo diretamente à proposta mais livre da coletânea anterior. Por tratar-se de um projeto de autoria dos dois países, a começar pela dupla de organizadores, o título Vaporpunk já anuncia que o foco de cenários e problemas brasileiros e portugueses será primordial.

Apesar de alguns contos não seguirem essa proposta, há no volume mundos detalhados criados pelos dois organizadores, além de pelos brasileiros Carlos Orsi, Eric Novello, Flávio Medeiros e Octavio Aragão, e dos portugueses João Ventura, Jorge Candeias e Yves Robert, em um exercício criativo focado em conspirações políticas nas quais informações históricas, geográficas e tecnológicas são enfatizadas. Tal recorrência revela uma visão editorial que prevê ênfase histórica e tecnológica como essencial ao steampunk.

O volume abre com o único texto caracterizado como conto da coletânea. Em "A fazenda-relógio", de Octavio Aragão, temos um bem-vindo detalhamento da oposição monarquia, indústria e abolição, a partir da criação das fazendas do título e do conflito entre antigos escravos, o maquinário rudimentar que os substituiu e os interesses do poder vigente, representados no conto pelo Barão de Mauá e pelo consorte real Conde D’Eu.

A trama opõe cenas que vão da alta cúpula do poder até seus efeitos tanto no caso de escravos libertos e revoltosos, como também de seus antigos senhores. O texto de Aragão é ágil e bem 
construído, especialmente o parágrafo no qual descreve os efeitos das ações de Mauá. O conto integra o universo de dois romances do autor, A mão que cria, de 2006, e A mão que destrói, de 2018. Se o segundo pode ser tratado como steampunk, o primeiro não, pois a trama é contemporânea, apesar de aludir a eventos que justamente seriam desenvolvidos no livro posterior e neste conto de Vaporpunk.

Em "Os oito nomes do Deus sem nome", de Yves Robert, temos um ponto de partida interessante: e se Portugal, na figura do príncipe real, tivesse recorrido a forças sobrenaturais africanas para fortalecer o domínio lusitano, em oposição ao domínio de Inglaterra e França? No universo de Robert, os ingleses tornaram-se exímios oponentes por sua potência tecnológica. Já os franceses, por sua vez, tem sua força política calcada na inteligência e na diplomacia. Já Portugal tornou-se um império que tem no comércio, na armada e na produção agrícola seus grandes diferenciais, a ponto de se cogitar uma aliança com uma reticente e subjugada Espanha.

O conto abre com uma coligação de espiões advindos das três nações, tendo à frente os republicanos lusitanos João Lourenço e Jaime Fernandes. O fato deste ser negro causa desconfiança e apatia por parte dos agentes inglês e francês. A dupla, apesar de reconhecer os avanços de Carlos I, teme o que acontecerá com Portugal após sua partida, além de idelogicamente desejar que o povo possa escolher seu governante. Tendo por ambientação inicial a África central e depois Sintra, o conto detalha história e tecnologia, bem como o conflito político que une os quatro personagens, num conflito que culmina na explicação do título, carecendo, porém, de um desenvolvimento melhor de seus personagens. 
Em "Os primeiros astecas na lua", de Flávio Medeiros Jr., temos o prenúncio - ao lado do último conto da coletânea anterior - de um universo mais amplo, de contexto europeu, que reúne personagens históricas e ficcionais a partir de uma premissa instigante: o que aconteceria se a Inglaterra tivesse por primeiro ministro H. G. Wells e, na França, Julio Verne tivesse chegado ao poder? A partir de uma trama envolvendo espionagem cujo protagonista é Mister Prendick - o narrador de A ilha do dr. Moureau, de Wells - o enredo nos mostra os dois países lutando pela soberania política do mundo.

Único conto que abre mão da ambientação brasileira ou portuguesa, a temática europeia serve de laboratório para Medeiros abarcar diversas obras literárias e temáticas, como os crimes de Jack, o Estripador, as investigações de Sherlock Holmes, a exploração da lua - prometida no título -, a perseguição ao homem invisível, as aventuras marítimas do Capitão Nemo e a máquina do tempo. Infelizmente, faltam páginas para desenvolver todos esses elementos, algo que Medeiros faria dois anos depois ao transformar essa premissa no romance A Guerra Fria Vitoriana (Draco, 2014).

Em "Consciência de Ébano", de Gerson Lodi-Ribeiro, o texto apresenta algumas construções e marcas de textualidades que tentam simular uma narrativa escrita no século $X I X$, o que se mostra um exercício estilístico interessante. Na linha temporal criada por Lodi-Ribeiro, Palmares passou de quilombo oprimido a estado independente, em conflito acirrado com portugueses ao sul e holandeses ao norte. Seu protagonista é um integrante dessa comunidade que enfrenta uma dura decisão: de um lado executar sua missão e, de outro, destruir a arma secreta de seus conterrâneos, um vampiro indígena chamado Dentes Compridos. Aqui a explicação 
cogitada para a criatura flerta com o evolucionismo de Darwin, enquanto a construção de uma hidrelétrica serve de pano de fundo para o conflito.

Lodi-Ribeiro apresenta uma boa premissa, revestida de uma narrativa por vezes empolgante, por vezes centrada em questões políticas. A descrição dos hábitos do vampiro e sua sede de sangue também é um dos pontos altos da narrativa, numa novela na qual o detalhamento tecnológico quase inexiste, estando o foco na história alternativa e seus efeitos sociais.

Num conto de guerra, Jorge Candeias cria em "Unidade em chamas" um conflito crescente entre rotina bélica, ideais étnicos e valores culturais. No conto, acompanhamos um piloto - ou "passarolista" - português chamado Sidónio e as dificuldades de sua tropa. O conflito aqui é duplo, não estando apenas na batalha iminente contra uma misteriosa ameaça como também pela chegada de uma tropa africana que vem em seu auxílio. A inserção racial é vista como ameaça pelo protagonista, sendo boa parte do conto dedicada ao debate das diferenças entre ele e seus aliados e no duro aprendizado através da batalha.

Além disso, a trama detalha uma série de armas e dirigíveis, rotinas militares e estratégicas de combate. O clima de tensão diante da batalha e os perigos decorrentes dela levam o leitor até o final, quando Sidónio tem de contar justamente com as forças que julgava ameaçadoras. Um conto cuja temática steampunk aparece em segundo plano em detrimento do ritual bélico e da crítica social.

Em "A extinção das espécies", de Carlos Orsi, acompanhamos a viagem de um jovem Charles Darwin pela América do Sul partindo 
do Rio de Janeiro e chegando à Patagônia. Lá, Darwin testemunha o conflito entre brasileiros sulistas e indígenas chilenos pela região, enquanto debate ciência, tecnologia e ética, com dois importantes interlocutores, um histórico, outro ficcional: o coronel Juan Manuel de Rosas e o professor Luis Adolfo Morel. O estilo de Orsi é fluido e elegante, resultando num texto mais leve e dinâmico que os anteriores, centrado no protagonista e em suas buscas científicas e existenciais.

A identidade de um personagem, chamado apenas de o Fabricador de Autômatos alemão, também desperta a curiosidade, propondo uma interessante reflexão entre as ideias evolucionistas do Darwin histórico - aqui associadas ironicamente a Alfred Russell Wallace - e as propostas por Mary Shelley em seu Frankenstein. A intersecção entre ficção e história e entre exploração geográfica e tecnológica estão entre os pontos altos do conto. Orsi não precisa para tanto alterar nem linha temporal nem cartografia. Antes, sua hipótese narrativa questiona até onde a tecnologia e a ciência nos levariam caso literatura e realidade se fundissem.

Ambientado no Rio de Janeiro, Eric Novello apresenta, em "Os dias da besta", um mistério envolvendo uma perigosa fera, então capturada por ingleses. Tendo por pano de fundo a futura Guerra do Paraguai, um Brasil avançado tecnologicamente e espiões a serviço ou não do império, uma das melhores ideias do conto é apresentar uma Princesa Isabel aviadora às voltas com um grupo de corsários e um Visconde de Taunay como inventor e agente secreto.

Com um clima investigativo interessante e uma ambientação mais do que adequada, Novello equilibra a descrição do mundo e da tecnologia desse Brasil alternativo com o enigma envolvendo a 
fera, até chegar à conclusão vertiginosa e bem-humorada, humor aliás que chega até às notas finais de sua história. É uma das novelas mais curtas do volume e uma das mais hábeis em entrecruzar conflito, caracterização e ambientação.

Finalizando o volume, "O sol é que alegra o dia...", de João Ventura, presta homenagem a uma figura um tanto obscura, mas não menos fascinante, da história portuguesa: a do inventor e clérigo António Manuel "Himalaya" Gomes. Dividido em pequenas seções, a narrativa é fluida e ágil, focada especialmente na vida de seu protagonista, indo de sua juventude à velhice, e nas suas invenções envolvendo energia solar.

Há um foco na descrição dos inventos de Himalaya, sugerindo - ao invés de uma história alternativa ou de um invento fantástico o quanto elementos surpreendentes e insólitos estão disponíveis na biografia de figuras históricas e em eventos de seus espaços e tempos. Esses temas também servem de pano de fundo para discussões atuais, como a oposição ciência versus religião e a relação entre interesses políticos e privados, muitas vezes deixando a dúvida se o autor está falando do passado ou do presente.

Enquanto análise do volume como um todo, usemos os critérios utilizados anteriormente. No que diz respeito ao uso do cenário, quatro autores - Aragão, Lodi-Ribeiro, Orsi e Novello - utilizam o Brasil em suas narrativas, enquanto outros três - Robert, Candeias e Ventura - fazem uso de cenários lusitanos, ficando apenas a novela de Medeiros como exceção à proposta do volume. 
TABELA II - ELEMENTOS DESCRITIVOS DOS CONTOS PUBLICADOS NA COLETÂNEA VAPORPUNK (DRACO, 2010)

\begin{tabular}{|c|c|c|c|c|c|}
\hline \multirow[b]{2}{*}{ CONTO E AUTOR } & \multirow[b]{2}{*}{ CENÁRIO } & \multicolumn{2}{|c|}{ AMBIENTAÇÃO } & \multicolumn{2}{|c|}{ CARACTERIZAÇÃO } \\
\hline & & $\begin{array}{c}\text { Detalhamento } \\
\text { Histórico/Geográfico }\end{array}$ & $\begin{array}{l}\text { Detalhamento } \\
\text { Tecnológico }\end{array}$ & $\begin{array}{l}\text { Aprofundamento } \\
\text { Psicológico }\end{array}$ & $\begin{array}{l}\text { Aprofundamento } \\
\text { do Conflito }\end{array}$ \\
\hline $\begin{array}{l}\text { "A fazenda-relógio", } \\
\text { de Octavio Aragão }\end{array}$ & Brasil, Rio de Janeiro & $\mathrm{x}$ & & & $\mathrm{x}$ \\
\hline $\begin{array}{c}\text { "Os oito nomes do Deus sem nome", } \\
\text { de Yves Robert }\end{array}$ & $\begin{array}{l}\text { Africa e Portugal, } \\
\text { Sintra }\end{array}$ & $\mathrm{x}$ & $\mathrm{x}$ & & $\mathrm{x}$ \\
\hline $\begin{array}{l}\text { "Os Primeiros Aztecas na Lua", } \\
\text { de Flávio Medeiros Jr. }\end{array}$ & $\begin{array}{c}\text { Europa, Inglaterra e } \\
\text { França }\end{array}$ & $\mathrm{X}$ & $\mathrm{X}$ & & $\mathrm{X}$ \\
\hline $\begin{array}{l}\text { "Consciência de Ébano", } \\
\text { de Gerson Lodi-Ribeiro, }\end{array}$ & Brasil, Palmares & $\mathrm{X}$ & & & $\mathrm{X}$ \\
\hline $\begin{array}{l}\text { "Unidade em chamas", } \\
\text { de Jorge Candeias }\end{array}$ & Europa, Portugal & $\mathrm{x}$ & $\mathrm{x}$ & & $\mathrm{x}$ \\
\hline $\begin{array}{c}\text { "A extinção das espécies", } \\
\text { de Carlos Orsi }\end{array}$ & $\begin{array}{c}\text { Brasil, Rio de Janeiro, } \\
\text { e Argentina }\end{array}$ & $\mathrm{x}$ & & $\mathrm{x}$ & $\mathrm{x}$ \\
\hline $\begin{array}{l}\text { "Os dias da besta", } \\
\text { de Eric Novello }\end{array}$ & Brasil, Rio de Janeiro & $\mathrm{x}$ & & & $\mathrm{x}$ \\
\hline $\begin{array}{l}\text { "O sol é que alegra o dia...", } \\
\text { de João Ventura }\end{array}$ & Portugal & $\mathrm{X}$ & $\mathrm{x}$ & $\mathrm{x}$ & \\
\hline
\end{tabular}

Quanto à ambientação, há aqui a mesma ênfase no detalhamento histórico, geográfico e tecnológico que vimos no volume anterior. Do mesmo modo, o aprofundamento de paisagens internas ou dramas psicológicos raramente se faz presente, estando o foco mais no conflito. Exceções à regra seriam Orsi, e o seu jovem Darwin, e Ventura, mas este apenas por seu conto carecer de conflito definido e constituir mais uma biografia curta do seu protagonista do que qualquer outra coisa.

Outro elemento que destacamos seria o excesso de tramas de espionagem, o que nos faz questionar se houve alguma orientação aos autores nesse sentido. Isso explica parcialmente o quanto o eixo Ambientação versus Caracterização acabou pendendo para o primeiro elemento, uma vez que a ênfase em tramas, guerras e conspirações políticas mais amplas acaba por fazer sombra sobre esforços caracterológicos ou psicológicos mais abrangentes. Coincidentemente, aqui também valeria a avaliação de Pegoraro sobre o volume de 2009, tendo as histórias de Vaporpunk, em sua maioria, o mesmo "pano de fundo bélico" e as disputas por "tecnologia" e "armamento" (2017, p.552). 
Por outro lado, esse mesmo fator dá ao volume uma unidade narrativa que serve de perfeita exemplificação do potencial ficcional do steampunk por parte de autores brasileiros e portugueses. Além disso, outro fator recorrente aos contos é o tema do preconceito étnico, uma vez que a oposição entre caucasianos e negros é enfatizada, por vezes tornando-se central ao enredo e ao conflito, como é o caso dos contos de Aragão, Robert, Lodi-Ribeiro e Candeias.

Como visto na seção anterior, foram vários os elementos presentes nas três obras de Jeter, Blaylock e Powers que seriam constitutivos do steampunk, entre eles: releitura de clássicos do século XIX; maior presença de personagens femininas,; conflito de classes; justaposição de temporalidades; valorização de personagens marginalizados; mescla de elementos ficcionais com dados históricos; presença de heróis regulares; revisitação de tropos comuns a ficção científica; revisão irônica desses temas e situações.

Quando contrastados com as obras inaugurais do steampunk no Brasil, algumas delas estão presentes. Já outras, não. Nas duas coletâneas, por exemplo, identificamos uma grande energia dedicada ao detalhamento dos mundos alternativos que resultam em situações políticas e culturais, inventos tecnológicos e tramas envolvendo aventura, conspirações e espionagem. Nesse aspecto, os contos parecem dialogar mais com um tipo específico de trama mais calcada na aventura do que na crítica social, algo que vimos como essencial do primeiro ímpeto do trio de autores californianos.

Por outro lado, se na superfície há essa ênfase na aventura e nos dramas políticos do período, por outro os autores trazem à tona uma questão que é essencial ao contexto brasileiro - e também 
perceptivel na sensibilidade lusitana: os conflitos decorrentes de situações étnicas. Em culturas nas quais a miscigenação é essencial à compreensão de uma determinada visão de sociedade, esse tema não poderia ser escamoteado, o que acaba por constituir uma das grandes qualidades dos dois livros.

Ao lado dessa caraterística, as histórias dos dois volumes frequentemente apresentam personagens marginais e/ou idealistas revolucionários, o que dá às narrativas curtas e longas um caráter de insatisfação social muito comum à contemporaneidade. Dito isso, é possível identificar uma linha de continuidade desde o surgimento do steampunk em 1979 até seu surgimento no Brasil trinta anos depois.

Além disso, é inegável o quanto, no seu exercício de releitura, filtragem e reciclagem de cenários, personagens e situações advindas do século XIX, o gênero constitui um profícuo laboratório de revisão histórica. Talvez aqui esteja, inclusive, um dos grandes potenciais do steampunk brasileiro. Se uma crítica possível ao Brasil é sua falta de memória e de valorização e manutenção do seu patrimônio tanto cultural quanto arquitetônico, o steampunk pode significar - ao objetivar uma audiência jovem - um possível (re)conhecimento de nossa bagagem histórica, tanto em suas conquistas sociais, tecnológicas e políticas quanto em seus débitos materiais e simbólicos para com gerações de oprimidos e escravizados. Roberto de Sousa Causo trata justamente disso em seu Posfácio ao livro Fantástico Brasileiro: 0 insólito literário do romantismo ao fantasismo (Arte \& Letra, 2018).

Por fim, destacamos uma carência sentida nas duas coletâneas, algo também comum no caso dos três romances que 
dão origem ao gênero nos EUA: a presença de autoria feminina. Apesar de em alguns contos analisados personagens femininas ganharem forma, o fato dos dois volumes apresentarem apenas autorias masculinas acaba por fragilizar esse elemento. Em 2011, essa ausência seria respondida com a publicação de SteamPink (Estronho), coletânea organizada por Tatiana Ruiz que apresentou contos exclusivamente de autoria feminina. Essa publicação trouxe outra sensibilidade ao steampunk nacional, com alguns contos também flertando com a fantasia e o terror e comunicando o quanto representatividades étnicas e de gênero seriam necessárias à criação de histórias inovadoras e instigantes. Felizmente, essa diversidade acabou se tornando prática comum em projetos similares posteriores.

\section{CONSIDERAÇÕES FINAIS}

Como visto, uma das características primordiais do modo narrativo conhecido como steampunk seria a revisão crítica dos temas políticos e sociais contemporâneos, porém alocados no ambiente oitocentista. Tal exercício ficcional propicia contrastar e questionar essas visões de mundo. Não raro, essas obras destacam personagens femininas e negras, além de outros grupos pouco favorecidos ou literalmente marginalizados nas narrativas tradicionais. Nesse sentido, a ficção steampunk trava grande diálogo com as distopias, por serem narrativas fortemente sociais, onde se faz a denúncia das desigualdades e dos perigos de comportamentos intolerantes. É como se o steampunk funcionasse como um caleidoscópio ficcional, histórico $e$ crítico, não apenas filtrando a realidade do mundo ou as realidades dos textos, como também 
distorcendo, alterando e recriando esses elementos, produzindo assim, diante da vista do observador ou da observadora, uma imagem igualmente revisionista e futurista, no sentido de alteração do presente e da percepção do passado, para nos levar a outra construção de futuro. Bruce Sterling, no ensaio "The User's Guide to Steampunk", afirma: "A lições mais importantes do steampunk não são a respeito do passado. Antes, são sobre a instabilidade e a impermanência do nosso próprio tempo" (2011, p.13).

Steampunk. Vapor Marginal. Punk do Vapor. Eis as aglutinações, justaposições, que este modo narrativo derivado da ficção científica apresenta. A partir delas, seu produto final, todavia, é algo novo, insólito e inovador. Mal sabiam Jeter, Powers e Blaylock, enquanto bebiam noite adentro no O'Hara's Pub, que suas histórias vitorianas produziriam um tipo de ficção popular de tamanho potencial. Mal sabíamos nós, brasileiros, que o steampunk se tornaria, ainda em 2011, uma das formas mais estimulantes e convidativas de revisarmos e revisitarmos a nossa própria história.

\section{REFERÊNCIAS}

CELLI, Gianpaolo (Org.) (2009). Steampunk: Histórias de um passado extraordinário. São Paulo: Tarja Editorial.

CHAVES, Jayme Soares (2015). Viagens Extraordinárias e ucronias ficcionais: uma possível arqueologia do steampunk na literatura. (Dissertação - Mestrado). Universidade do Estado do Rio de Janeiro.

JETER, Kevin W. (1979). Morlock Night. Oxford: Angry Robot.

LODI-RIBEIRO, Gerson; SILVA, Luís Filipe (Orgs.) (2010). VaporPunk: Relatos Steampunk Publicados sob as Ordens de Suas Majestades. São Paulo: Draco.

MATANGRANO, Bruno; TAVARES, Enéias (2018). Fantástico brasileiro: o insólito literário do romantismo ao fantasismo. Curitiba: Arte \& Letra. 
PEGORARO, Éverly (2017). “A Experiência Urbana Steampunk: Entre a Literatura de Ficção Científica e as Ruas do Brasil". Revista Iberoamericana, LXXXIII, 547-563. PERSON, Lawrence (1998). “Notes Toward a Postcyberpunk Manifesto". In https:// news.slashdot.org/story/99/10/08/2123255/notes-toward-a-postcyberpunkmanifesto Acesso em 4.Jul.2019.

POWERS, Tim (2011). "Introduction”. In: JETER, Kevin W. Morlock Night. Oxford: Angry Robot.

ROBB, Brian J. (2012). Steampunk: An illustrated history of fantastical ficcion, fancivul film and other victorian visions. Voyageur Press.

ROBERTS, Adam K. (2010). “W. Jeter, Morlock Night”. In: JETER, Kevin W. Morlock Night. Oxford: Angry Robot.

STERLING, Bruce (2011). "The User's Guide to Steampunk". In: VANDERMEER, Jeff; CHAMBERS, S. J. The Steampunk Bible - an illustrated guide to the world of imaginary airships, corsets and goggles, mad scientists, and strange literature. New York: Abrams Image, p.12-13.

VANDERMEER, Jeff; CHAMBERS, S. J. (2011). The Steampunk Bible - an illustrated guide to the world of imaginary airships, corsets and goggles, mad scientists, and strange literature. New York: Abrams Image.

VIEIRA, Telma Maria (2016). "A diversidade dos gêneros discursivos: da ficção científica ao steampunk". REGIT - Revista de Estudos de Gestão, Informação e Tecnologia, v. 5, n. 1. Itaquaquecetuba, SP: FATEC, 15-25. In https://goo.gl/ AdhqGc Acesso em 11.Fev.2018. 